\title{
A rare etiology of diffuse pulmonary hemorrhage
}

\author{
Martin Janík', Veronika Rybárová', Lubomír Straka', Petr Hejna² \\ 'Department of Forensic Medicine, Jessenius Faculty of Medicine, Comenius University, University Hospital, Martin, Slovakia \\ ${ }^{2}$ Department of Forensic Medicine, Faculty of Medicine, Charles University and University Hospital, Hradec Kralove, Czech Republic
}

A 36-year-old drug addict presented to the emergency room after intravenously injecting 20 milliliters of pure gasoline. At the initial evaluation, he had complained of severe "freezing" chest pain and raging thirst. He provided a remote history of intravenously injecting low doses of gasoline. The admission examination was notable for a pronounced scent of gasoline on his breath, hypotension, and respiratory distress with diffuse rhonchi throughout the lungs. The laboratory workup showed severe metabolic acidosis, leukocytosis with neutrophilia, and markedly elevated serum myoglobin. The patient was treated with corticosteroids and maximum supportive care but there was no improvement. A chest radiograph was not performed given the patient's rapid decline. He soon developed large-volume hemoptysis and died without a definitive diagnosis 4 hours after presentation to the hospital. Postmortem examination was significant for diffusely enlarged and blood-filled lungs (Figure 1A, B). The left lung weighed $1780 \mathrm{~g}$ and the right lung weighed $1890 \mathrm{~g}$ (a normal lung weighs $\sim 300-400 \mathrm{~g}$ ). Microscopically, all lung sections demonstrated diffuse areas of fresh hemorrhage (Figure 1C). Thickened alveolar septa contained many neutrophils with dilated capillaries consistent with capillaritis (Figure 1D). There were also prominent hemosiderin-filled alveolar macrophages that showed evidence of previous alveolar hemorrhage (Figure 1E). Targeted toxicology confirmed a high concentration of hydrocarbons in the postmortem blood.
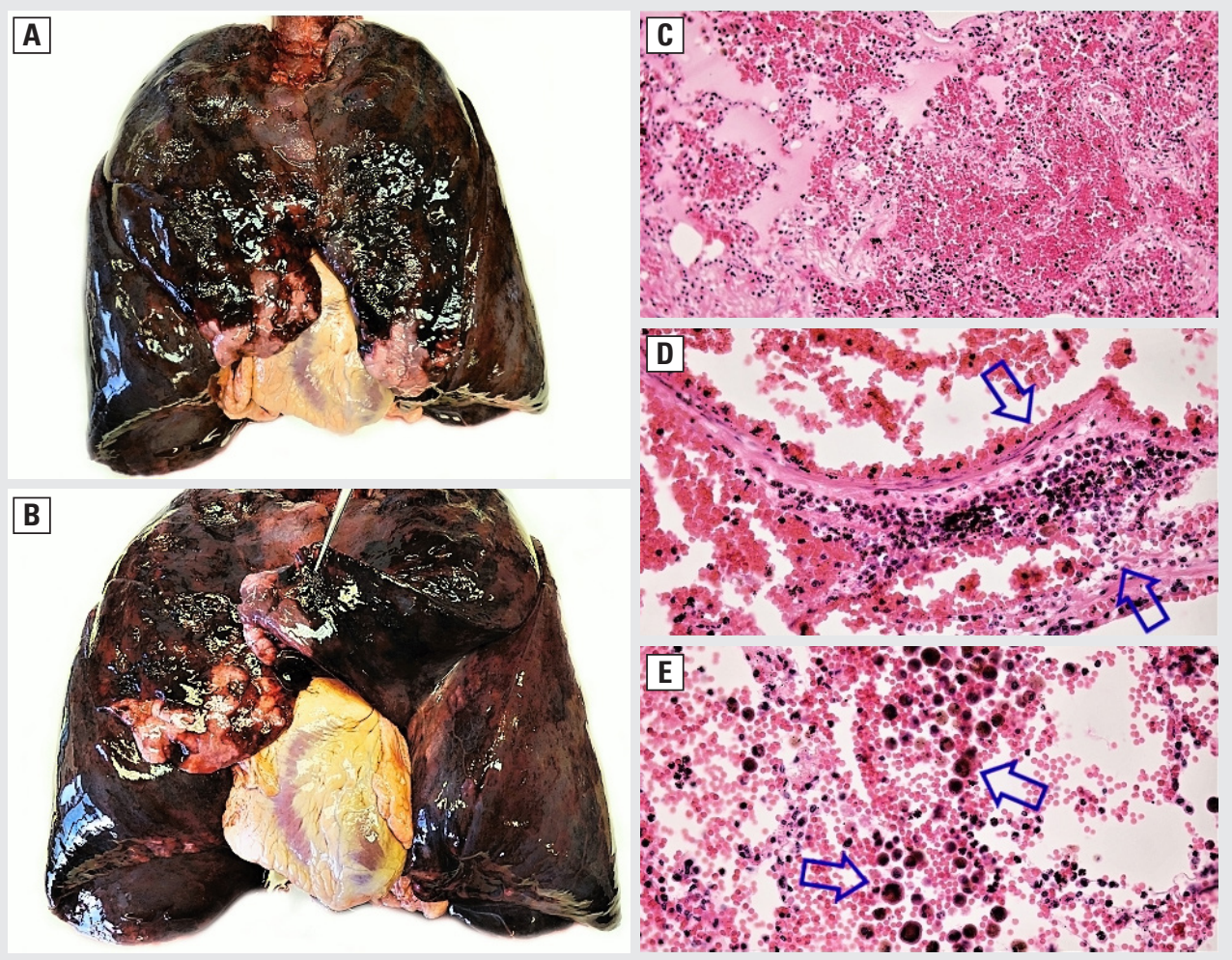

Figure 1 A Anterior surface of the severely blood-filled lungs B Interlobular surface with prominent areas of fresh hemorrhage C Acute alveolar hemorrhage with fibrin and edematous fluid (H\&E $\times 20$ ) D Capillaritis (blue arrows) surrounded by red cells (H\&E $\times 40$ ) E Prominent hemosiderin-filled alveolar macrophages (blue arrows) with associated fresh hemorrhage (H\&E $\times 40$ )

Address for correspondence: Martin Janik, Comenius University, Jessenius Faculty of Medicine, Martin, Slovakia; e-mail: janik.mato@gmail.com

DOI: 10.5603/ARM.a2020.0194 | Received: 28.08.2020 | Copyright (C) 2021 PTChP | ISSN 2451-4934 | e-ISSN $2543-6031$

Conflict of interest: None declared

This article is available in open access under Creative Common Attribution-Non-Commercial-No Derivatives 4.0 International (CC BY-NC-ND 4.0) license, allowing to download articles and share them with others as long as they credit the authors and the publisher, but without permission to change them in any way or use them commercially. 
Diffuse alveolar hemorrhage (DAH) refers to a distinct subset of pulmonary hemorrhage with widespread bleeding into alveoli, presumably because of injury to lung microcirculation [1]. DAH can occur in many clinical settings including vasculitides, autoimmune and coagulation disorders, and infections. Although uncommon, a number of medications and toxins such as anticoagulants, anti-arrhythmic drugs, and cocaine have been reported to cause DAH [2]. Intravenous gasoline is directly toxic to the lung microcirculation and carries a poor prognosis, although survival has been achieved [3]. The radiological features and the symptoms of gasoline toxicity are non-specific and dose-related. Nonetheless, a striking ice cold sensation in the chest (owing to exhalation of the volatile gasoline vapors) may be a useful diagnostic clue in an appropriate clinical context.

\section{References:}

1. Fijołek J, Wiatr E, Jakubowska L, et al. Diffuse alveolar haemorrhage complicated by pulmonary embolism - problems with treatment. Adv Respir Med. 2017; 85(6): 328-332, doi: 10.5603/ARM.2017.0056, indexed in Pubmed: 29288482.

2. Papanikolaou IC, Makou I, Markatis E. Amiodarone and diffuse alveolar hemorrhage. Adv Respir Med. 2020; 88(2): 169-171, doi: 10.5603/ARM.2020.0095, indexed in Pubmed: 32383473.

3. Fink K, Kuehnemund A, Schwab T, et al. Suicide attempt by intravenous injection of gasoline: a case report. J Emerg Med. 2010; 39(5): 618-622, doi: 10.1016/j.jemermed.2008.08.013, indexed in Pubmed: 19217240. 